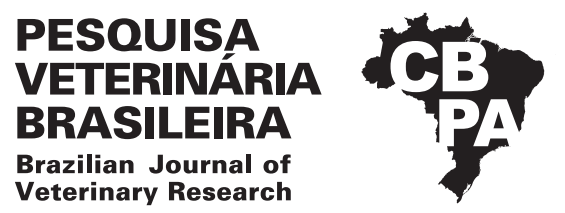

Pesq. Vet. Bras. 39(6):419-428, June 2019 DOI: 10.1590/1678-5150-PVB-5898

Original Article

Animal Morphophysiology

ISSN 0100-736X (Print)

ISSN 1678-5150 (Online)

\title{
Musculoskeletal ultrasonography of the elbow joint in dogs: applicability and evaluation protocol $^{1}$
}

\author{
Gabriela M.C. Bellegard²* (D), Érika R. Lopes², Shayne P. Bisetto² \\ and Maria Cristina F.N.S. Hage ${ }^{2}$ (it)
}

\begin{abstract}
Bellegard G.M.C., Lopes E.R., Bisetto S.P. \& Hage M.C.F.N.S. 2019. Musculoskeletal ultrasonography of the elbow joint in dogs: applicability and evaluation protocol. Pesquisa Veterinária Brasileira 39(6):419-428. Setor de Diagnóstico por Imagem, Faculdade de Zootecnia e Engenharia de Alimentos, Universidade São Paulo, Avenida Duque de Caxias Norte 225, Zona Rural, Pirassununga, SP 13635-900, Brazil.E-mail: gabi_bellegard@hotmail.com

The elbow is a complex joint and has great clinical relevance in small animal medicine. Previous research in this area has been performed using radiographic and tomographic methods; however, there are limited studies on ultrasonography. The aims of this study was suggesting an evaluation protocol for elbow scan and describe the ultrasonographic anatomy of the elbow joint in dogs. Ten cross-breed dogs weighing $5-15 \mathrm{~kg}$ underwent radiography and were selected for this ultrasonographic study. The protocol was established for the ultrasonographic description dividing the articular areas in the proximal, middle, and distal, lateral, cranial, medial, and caudal faces. The approach was performed in the longitudinal, transverse and oblique planes and the musculoskeletal structures were described according to the architecture, echogenicity and echotexture. Computed tomography and magnetic resonance imaging scans were obtained for one animal for comparison. Ultrasonography was effective in visualizing and analyzing muscles, tendons and ligaments. Bone contours and regions that have clinical significance such as the medial coronoid process and anconeus process were identified, but with limited access. Prior knowledge of the normal sonographic anatomy of the elbow joint, as well as its technical advantages and limitations will allow further studies related to the identification of musculoskeletal disorders.
\end{abstract}

INDEX TERMS: Musculoskeletal ultrasonography, elbow joint, canine, articulation, diagnostic imaging, standardization, dogs, morphology.

RESUMO.- [Ultrassonografia musculoesquelética da articulação do cotovelo em cães: aplicabilidade e protocolo de avaliação.] 0 cotovelo é uma articulação complexa e tem grande relevância clínica na medicina veterinária de pequenos animais. Pesquisas prévias nesta área foram realizadas utilizando radiografias e tomografia computadorizada, entretanto há limitados estudos com ultrassonografia. 0 objetivo desse estudo é sugerir um protocolo de avaliação da articulação do cotovelo e descrever sua anatomia ultrassonográfica. Dez cães sem raça definida, pesando $5-15 \mathrm{~kg}$ foram submetidos à radiografias e foram selecionados para o estudo ultrassonográfico. 0 protocolo

\footnotetext{
${ }^{1}$ Received on October 11, 2018.

Accepted for publication on January 28, 2019.

${ }^{2}$ Faculdade de Zootecnia e Engenharia de Alimentos (FZEA), Universidade de São Paulo (USP), Campus Fernando Costa, Avenida Duque de Caxias Norte 225, Pirassununga, SP 13635-900, Brazil.E-mail: gabriela_bellegard@usp.br, erika_rondon10@hotmail.com, shaynebisetto@yahoo.com; *Corresponding author: gabi_bellegard@hotmail.com
}

foi estabelecido para a descrição anatômica ultrassonográfica dividindo as articulações em proximal, média e distal, faces lateral, cranial, medial e caudal. A abordagem foi realizada nos planos longitudinal, transverso e oblíquo e as estruturas foram descritas de acordo com a arquitetura, ecogenicidade e ecotextura. Tomografia computadorizada e ressonância magnética foram realizadas em um animal para comparação. A ultrassonografia foi efetiva na visualização e análise de músculos, tendões e ligamentos. Os contornos ósseos e regiões com significado clínico como o processo coronóide medial e o processo ancôneo foram identificados, mas com acesso limitado. Conhecimento prévio da anatomia ultrassonográfica normal da arquitetura do cotovelo, bem como suas vantagens e limitações, irão permitir estudos adicionais relacionados à identificação de desordens musculoesqueléticas.

TERMOS DE INDEXAÇÃO: Ultrassonografia musculoesquelética, articulação do cotovelo, caninos, articulação, diagnóstico por imagem, padronização, morfologia. 


\section{INTRODUCTION}

Ultrasonography is a modality of diagnostic imaging that can be used to complement radiographic imaging in evaluating the musculoskeletal system (Samii \& Long 2002, Knox et al. 2003, Villamonte-Chevalier et al. 2015b).

There is prevalent interest in finding alternative techniques to evaluate the joints, and ultrasound can pass easily through soft tissue and provides details of the bone surfaces. High definition equipment can provide information similar to that obtained with magnetic resonance imaging (Nazarian 2008). This is a dynamic imaging tool that can be used both during flexion and extension, and it is cost-effective, non-invasive, and does not require sedation or anesthesia (Samii \& Long 2002, Knox et al. 2003).

Thoracic limb injuries in dogs with clinical signs of claudication are often related to elbow diseases (Cook \& Cook 2009a). This joint has a complex structure and bio-mechanical physiology, and is of great importance to clinicians (Van der Meulen 2013). The elbow joint is commonly evaluated by radiography initially, especially in elbow dysplasia (Gielen et al. 2012), but apparently normal elbows in radiographs could be false negative in some cases (Sendyk-Grunkraut et al. 2017). Computed tomography and magnetic resonance imaging are also techniques that can be used, but these modalities are expensive and most of the times requires anesthesia (De Rycke et al. 2002, Cook \& Cook 2009b). Even though these techniques are considered the gold standard (Sendyk-Grunkraut et al. 2017), they should be considered in cases when alternative technique findings are inconclusive (Brienza \& Lacreta Júnior 2013).

Previous research in this area has been conducted using radiography and computed tomography; however, there are few studies using ultrasonography. Our study intended to evaluate the normal elbow joint of 10 healthy dogs by using ultrasonography and thereby suggest a suitable protocol that can help students and professionals to identify the elbow structures and reproduce the images for learning and help in their diagnosis.

\section{MATERIALS AND METHODS}

The project was approved by the Animal Experimentation Ethics Committee of FZEA-USP with protocol number 14.1.1490.74.0. Ten cross-breed dogs, weighing $5-15 \mathrm{~kg}$ with no signs or history of claudication were selected. Before ultrasonographic evaluation, the animals underwent a complete blood count and measurement of the levels of urea and creatinine, alanine aminotransferase, aspartate aminotransferase, and alkaline phosphatase. Dogs with normal blood test results were forwarded to radiographic examination by analogical method, anesthesia was made when it needed. The thoracic limbs were evaluated in the mediolateral, craniocaudal and craniolateral-caudomedial directions as well as in the mediolateral direction during flexion. Dogs that showed any radiographic alteration were excluded from the ultrasonographic screening. Clinical, radiographic and ultrasonographic analysis was made by the postgraduate student, ex-resident student, in imaging diagnosis (G.M.C.B) with master's supervisor (M.C.F.N.S.H) care. During the project was notice a learning curve of the techniques that were performed.

\section{Ultrasonographic study}

Ultrasonography was performed with an Esaote ${ }^{\circledR}$ My Lab Class $C$ Vet, equipped with a high frequency linear transductor (LA 533 8-13 MHz), for this study $10 \mathrm{MHz}$ frequency was the most used. For a better image quality, hair from the middle humerus to the middle forearm was shaved in all dogs, except one, for which we used only alcohol and acoustic gel. All dogs were held in the lateral (right or left) decumbency position for the examination, with the limbs in extension or flexion depending on the region that was evaluated. The use of standoff was not necessary in this study.

\section{Evaluation protocol for ultrasonography examinations}

The elbow joint was divided into the proximal (distal humerus), middle (elbow joint) and distal regions (proximal forearm). The screening was started at the middle third of the humerus until the middle third of the radius and ulna. The joint was also divided into cranial, lateral, medial, and caudal faces.

Lateral face. The evaluation was performed with the limbs extended. Initially, the probe was placed in the longitudinal plane of the proximal region and the screening was performed from the cranial to caudal direction, approaching the cranio-lateral and caudo-lateral aspect. Then, the probe was placed in the middle region, taking the lateral epicondyle of the humerus as a reference, and the screening was performed in the same way. Finally, the transductor was placed in the distal region and the procedure was performed in the same way (Fig.1A).

Cranial face. The thoracic limbs were evaluated in the extension position. Screening of the middle aspect was performed with the probe placed in the longitudinal plane from the lateral to medial direction, approaching the cranio-lateral and cranio-medial faces (Fig.2A).

Medial face. The evaluation was made with the limb extended in the longitudinal plane. Initially, the proximal region was screened from the cranial to caudal direction, approaching the craniomedial and caudo-medial faces. Then, the probe was placed in the middle region, taking the medial epicondyle of the humerus as a reference, and the screening was performed in the same way. Finally, the same procedure was performed in the distal region (Fig.3A).

Caudal face. The evaluation was started with the probe placed in the middle region, with the limb extended in the longitudinal plane. The screening was first performed from the lateral to medial direction (Fig.4A). Then, the screening was performed in the same way but with the limb in flexion (Fig.5A). Subsequently, the probe was placed on the edge of the proximal and middle region in a transverse plane with the limb extended. The screening was performed from the proximal to distal direction (Fig.6A).

\section{Complementary studies}

The Veterinary Anatomy Laboratory of the Faculty of Animal Science and Food Engineering of the University of São Paulo (FZEA-USP, Pirassununga/SP, Brazil) provided anatomical structures and sections in transverse and longitudinal planes for elbow joint anatomical study. The sections were photographed and images of the anatomical structures were compared with the images obtained by radiography, ultrasonography, MRI, and CT scans of the region. Radiographic studies of the selected dogs were conducted before the mean study to a previous evaluation. Computed tomography ${ }^{1}$ and

${ }^{1}$ CT images were acquired using Shimadzu ${ }^{\circledR}$, helical, model SCT-7800. 


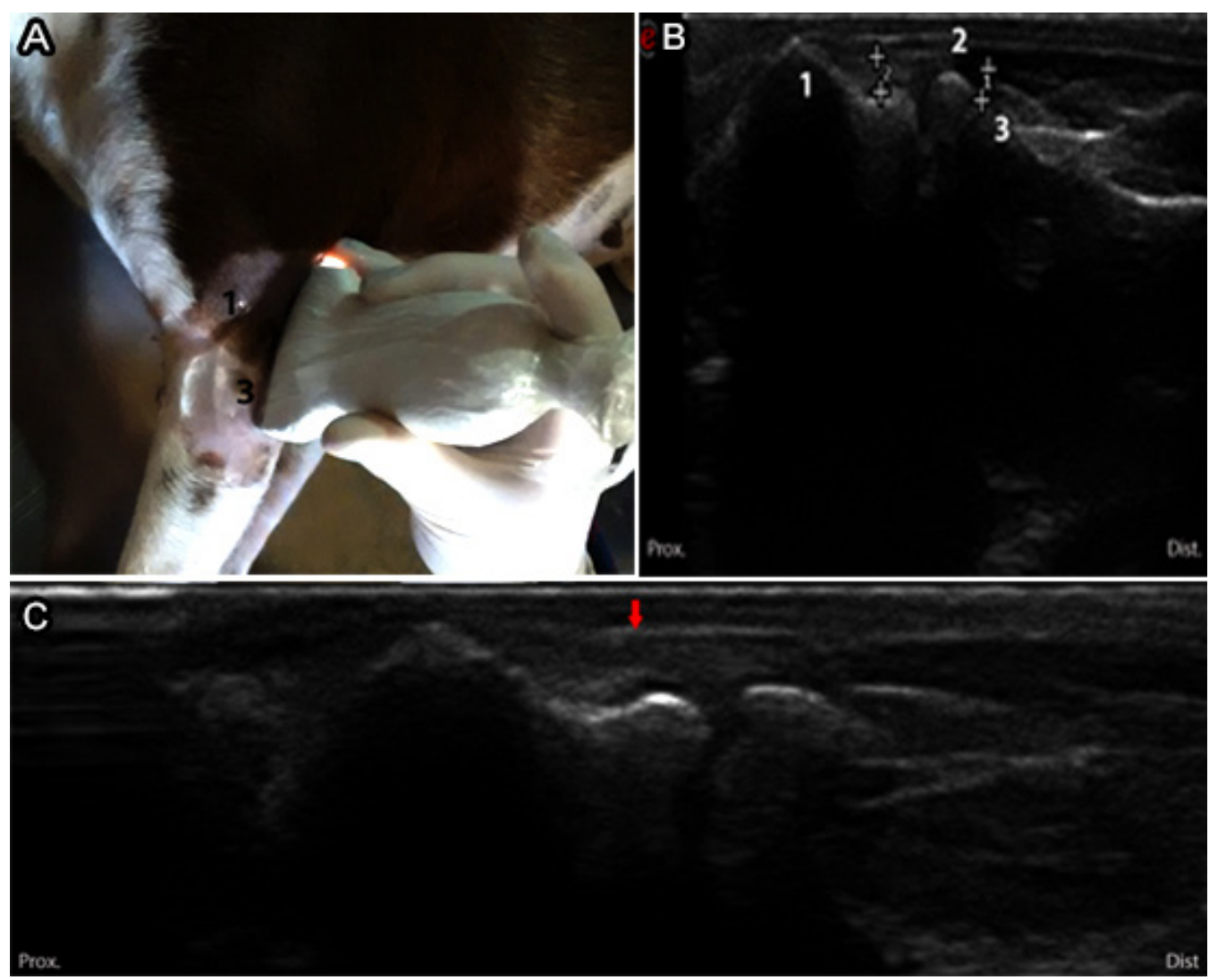

Fig.1. (A) Transducer positioning showing the topographic region of the structures of the lateral aspect of the elbow. Cranial (Cra.) and caudal (Cau.). (B) Ultrasonographic image corresponding to the assessed region. Lateral epicondyle of the humerus (1), lateral collateral ligament (2) and radius head (3). (C) Ultrasonographic image of the lateral collateral ligament (red arrow).

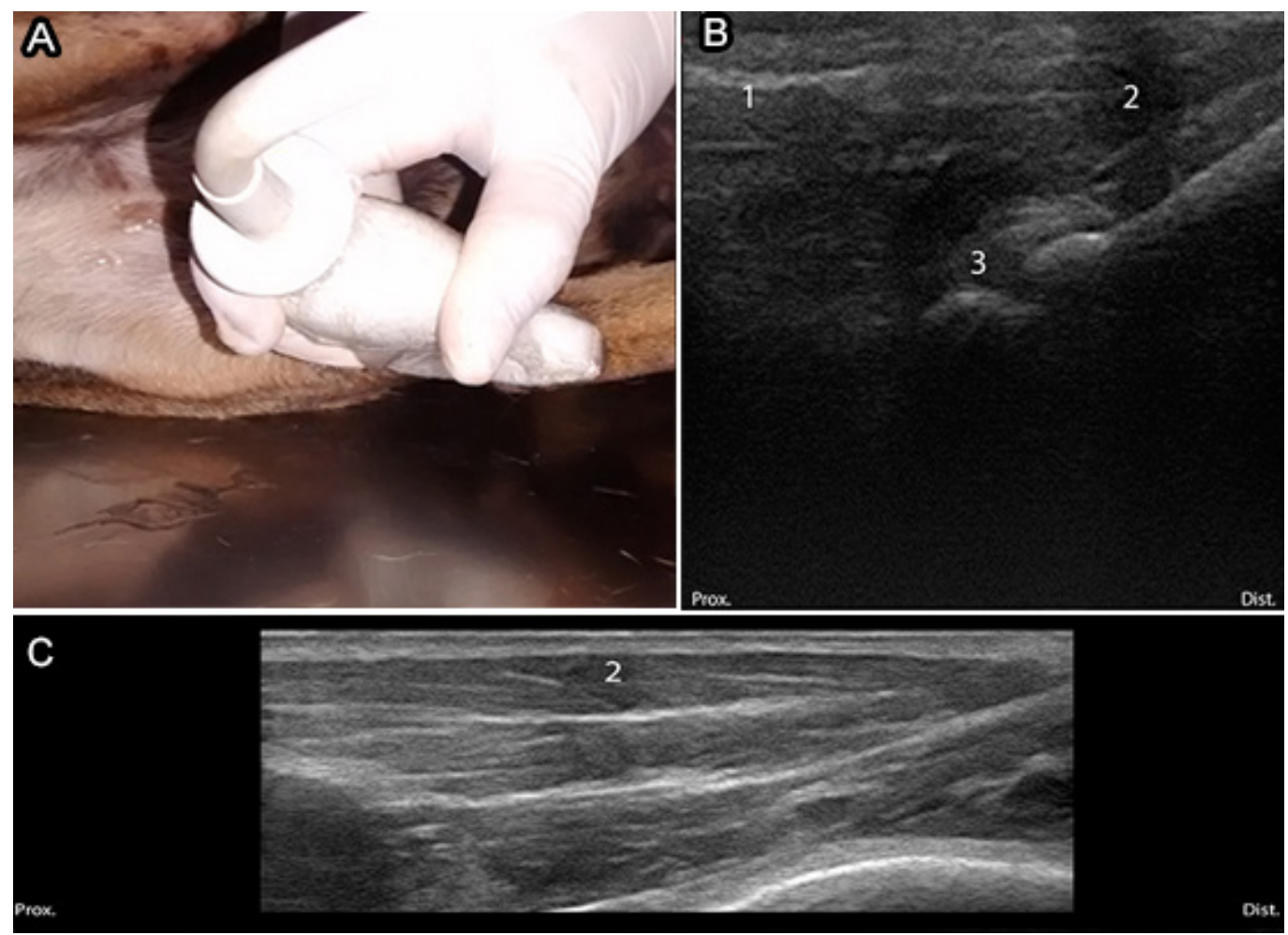

Fig.2. (A) Transducer positioning showing the topographic region of the structures of the cranial aspect of the elbow. (B,C) Ultrasonographic image corresponding to the assessed region. Brachial/brachial biceps muscle (1), extensor carpi radialis muscle (2) and joint space (3). 

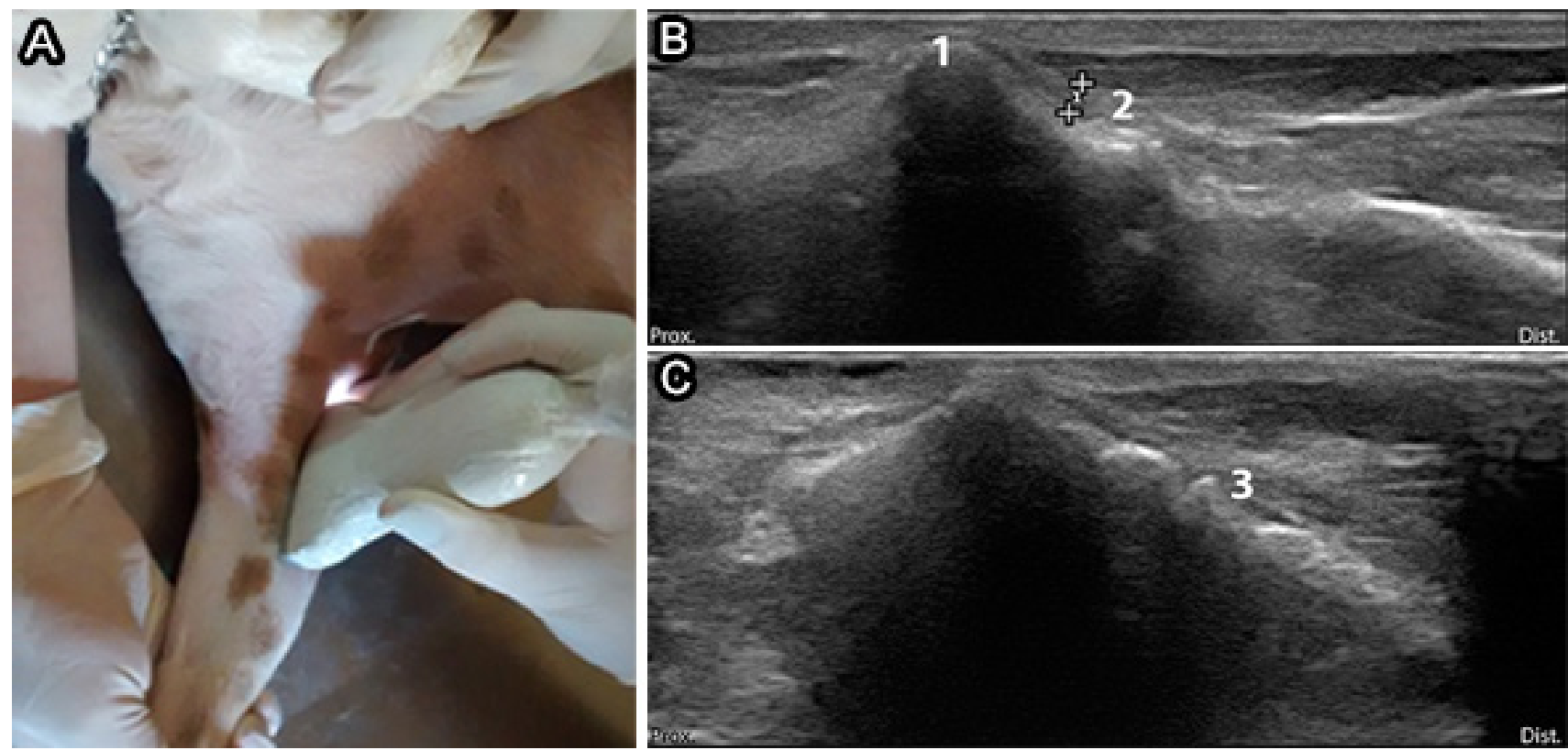

Fig.3. (A) Transducer positioning showing the topographic region of the structures of the medial aspect of the elbow. (B,C) Ultrasonographic images corresponding to the assessed region, with the limb in extension. Bone surface of the distal humerus (1), medial collateral ligament (2) and medial coronoid process of the ulna (3).

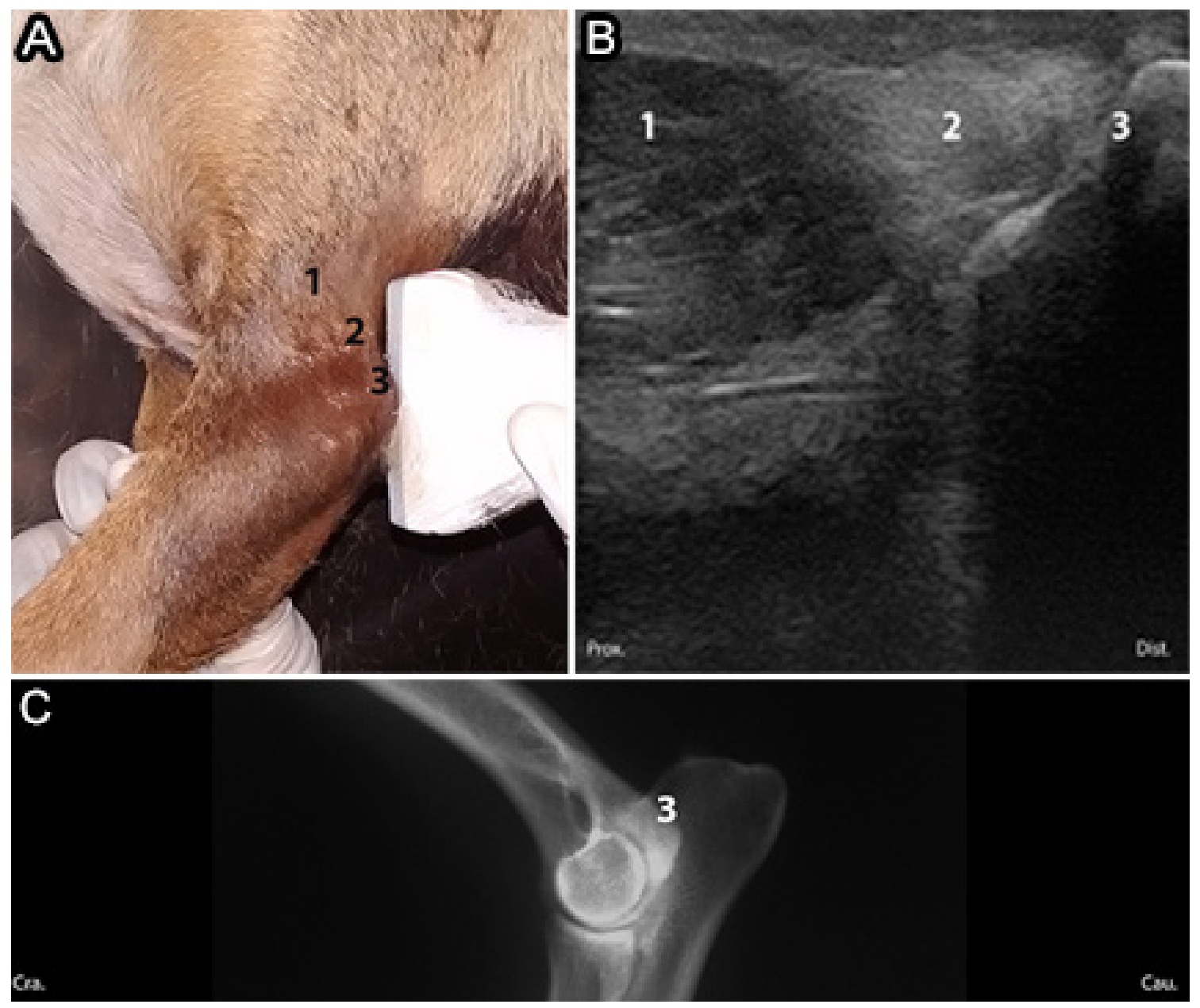

Fig.4. (A) Transducer positioning showing the topographic region of the structures of the caudal aspect of the elbow in extension. (B) Ultrasonographic image corresponding to the assessed region. Triceps brachii muscle (1), triceps brachii muscle tendon (2) and olecranon (3). (C) Radiographic image in the mediolateral projection of the elbow joint in a neutral position for comparison. 

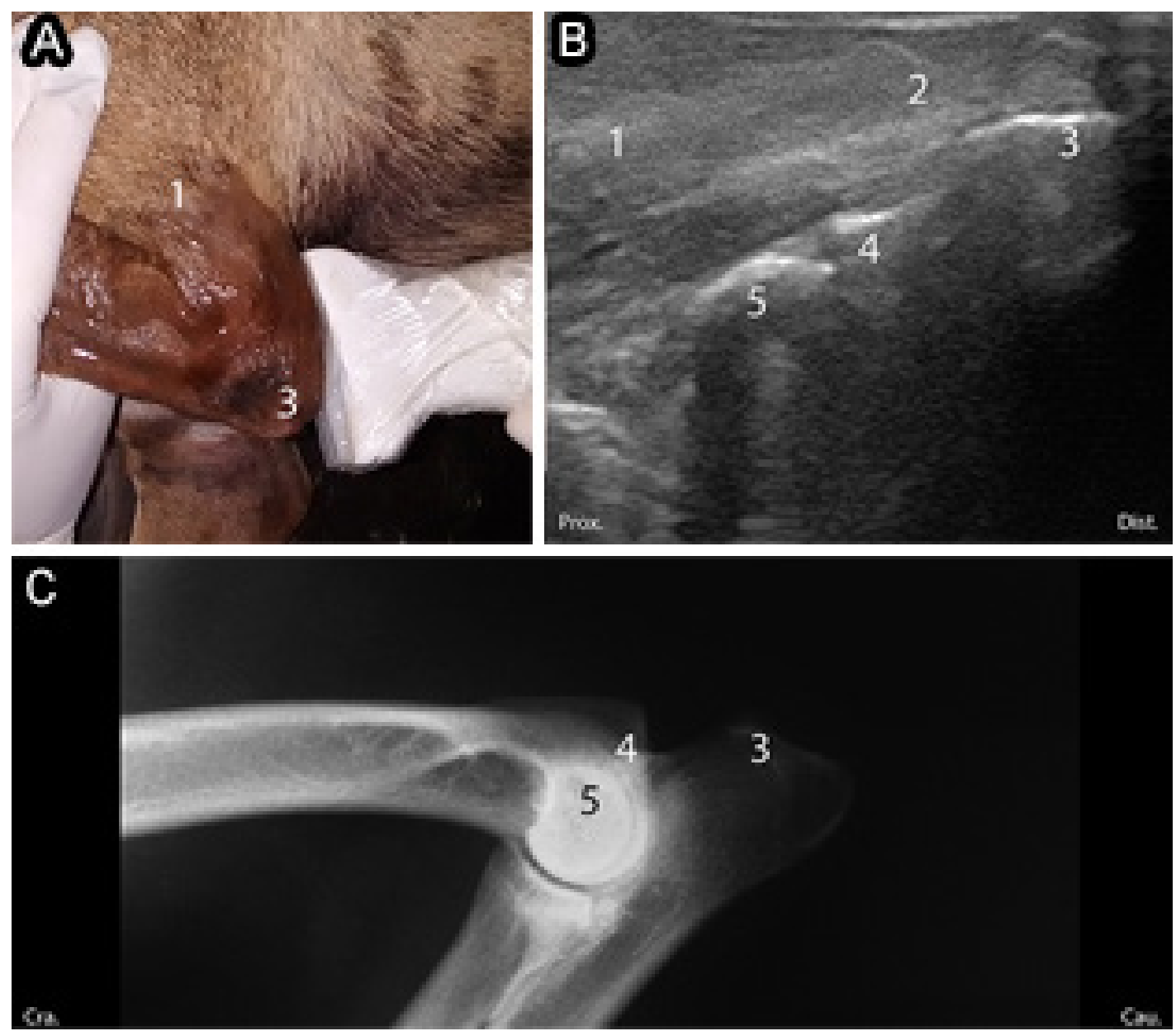

Fig.5. (A) Transducer positioning showing the topographic region of the structures of the caudal aspect of the elbow in flexion. (B) Ultrasonographic image corresponding to the region evaluated with the limb. Triceps brachii muscle (1), triceps brachii muscle tendon (2), olecranon (3), anconeal process (4) and humeral condyle (5). (C) Radiographic image in the mediolateral projection of the elbow joint in flexion for comparison.
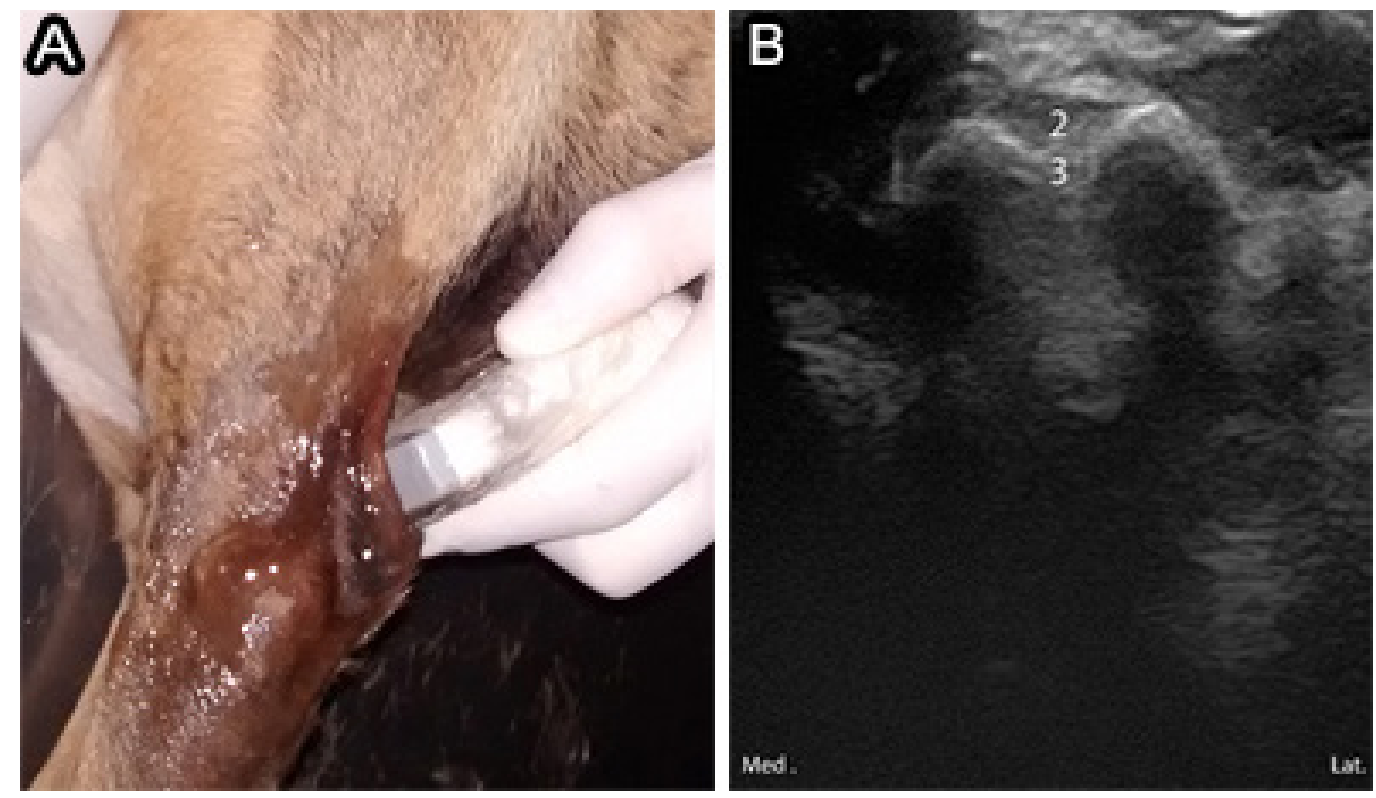

Fig.6. (A) Transducer positioning showing the topographic region of the structures of the caudal aspect of the elbow. (B) Ultrasonographic image corresponding to the region evaluated in the transverse plane. Triceps brachii muscle tendon (1), subtendinous bursa of the tendon of the triceps brachii muscle (2) and olecranon (3). 
Table 1. Identification of the structures of the elbow joint by the ultrasonographic method in comparison to the other diagnostic imaging techniques

\begin{tabular}{|c|c|c|c|c|}
\hline \multirow{2}{*}{ Structures } & \multicolumn{4}{|c|}{ Imaging technique } \\
\hline & $\mathrm{XR}$ & US & $\mathrm{TC}$ & MR \\
\hline Humeral surface & +++ & ++ & +++ & ++ \\
\hline $\begin{array}{l}\text { Lateral condyle of the } \\
\text { humerus }\end{array}$ & ++ & + & +++ & ++ \\
\hline Lateral collateral ligament & - & +++ & - & + \\
\hline Articular space & + & ++ & +++ & +++ \\
\hline Radius surface & +++ & ++ & +++ & ++ \\
\hline Ulnar surface & ++ & ++ & +++ & ++ \\
\hline $\begin{array}{l}\text { Medial condyle of the } \\
\text { humerus }\end{array}$ & ++ & + & +++ & ++ \\
\hline Medial collateral ligament & - & +++ & - & + \\
\hline $\begin{array}{l}\text { Medial coronoid process of } \\
\text { the ulna }\end{array}$ & + & + & +++ & ++ \\
\hline Flexors muscles & - & +++ & + & ++ \\
\hline Triceps brachii muscle & - & +++ & + & ++ \\
\hline Triceps brachii muscle tendon & - & +++ & - & +++ \\
\hline Olecranon & ++ & + & +++ & ++ \\
\hline Anconeal process & ++ & + & +++ & ++ \\
\hline $\begin{array}{l}\text { Subtendinous bursa of the } \\
\text { triceps brachii muscle }\end{array}$ & - & ++ & - & - \\
\hline Extensors muscles & - & +++ & + & ++ \\
\hline Brachii/biceps brachii muscle & - & +++ & + & ++ \\
\hline
\end{tabular}

magnetic resonance imaging ${ }^{2}$ scans were obtained for one animal as an additional part of this study to compare the additional findings of these techniques.

In this study, different diagnostic imaging tests were compared regarding the quality of visibility of the previously described structures identified on ultrasonography. The analysis was performed by checking the images; these were analyzed by the examiner and compared with the information in the literature. They were divided into unidentified structures, structures with poor visibility, structures with moderate visibility, and structures with excellent visibility (Table 1).

A subjective evaluation was made considering the superinposition or not of the studied structures, the complete or partial identification and the detailing, according to the limitation of each technique.

\section{RESULTS}

During the ultrasonography examinations, all the dogs were co-operative, except one, which required tranquilization for radiographic and ultrasonographic evaluation. Radiographic study was used as an exclusion criterion and it allowed the initial evaluation of the bone and articular structure, even though this technique did not exclude all the articular injuries. One limb each from four of the animals was excluded from the experimental group because of the presence of periarticular osteophytes and pre-existing fracture.

Ultrasonographic assessment was performed according to the proposed evaluation protocol. All the dogs that have been evaluated didn't show ultrasonographic changes.

\footnotetext{
${ }^{2}$ MRI images were acquired using Esaote ${ }^{\circledR}$ model Vet MR Grande - 0.25 Tesla.
}

The lateral face of the elbow joint was the first region of study. Muscular structures were visible as hypo-echogenic areas with parallel hyper-echogenic lines in between. The brachii muscle was located in the cranio-lateral section adjacent to the humeral surface. In the caudo-lateral section, the distal portion of the triceps brachii muscle was identified; the extensor muscles were distal to the elbow joint in the cranio-lateral section of the forearm. The bone surfaces of the humerus and radius head were characterized as intense hyper-echogenic lines with acoustic shadows. The collateral lateral ligament was observed as fine hyper-echogenic parallel lines originating in the lateral humerus epicondyle and adjacent lateral bone surfaces (Fig.1B).

In the longitudinal plane of the cranial face, the articular space was identified as a gap between the bone surfaces of the distal region of the humerus condyle and the proximal region of the radius. The biceps brachii muscle and brachii muscle were observed in the proximal portion in relation to the elbow joint. Distally, in the forearm region, the carpus radialis extensor muscle was identified (Fig.2B).

The triceps brachii muscle was seen in the longitudinal plan of the proximal region in the caudo-medial portion of the medial face of the elbow joint. In the craniomedial portion in the proximal region of the medial face, the biceps brachii muscle could be seen. In the forearm region in the caudo-medial portion, it could be identified the flexors muscle group.

In the longitudinal plane at the middle region of the medial face, a curved hyper-echogenic surface was characterized as the distal portion of the humerus, corresponding to the medial epicondyle. The medial collateral ligament had the same characteristics as the lateral collateral ligament and originated in the medial humerus epicondyle. Oblique sections were obtained for characterization of the medial coronoid process, because it could not be seen at the same plane as the collateral medial ligament (Fig.3B).

The caudal face of the elbow joint was analyzed with the thoracic member in extension and flexion. The triceps brachii muscle and its tendon were identified in the longitudinal plane. Hyper-echogenic parallel lines with insertion in the olecranon were observed in the middle region of the joint. The anconeal process was seen as a hyper-echogenic curved line, forming acoustic shadows, identified on flexed limbs (Fig.4B and 5B).

In the transverse cross-section of the middle region of the caudal face of the elbow, the triceps brachii muscle tendon, subtendinous bursa of the triceps brachii muscle, and the olecranon surface were identified. A hyper-echogenic structure was observed in the superficial region, corresponding to the tendon and subtendinous bursa, which was iso-echogenic to the muscle region between the tendon and the olecranon bone surface (Fig.6B).

Computed tomography (CT) could evaluate the elbow joint in the transverse section without superpositioning. This is an important advantage over radiographic and ultrasonography exams. Furthermore, could clearly characterized the bone structure, especially in the region of the medial coronoid process (Fig.7B,C) and provides a great perception of elbow congruence. 

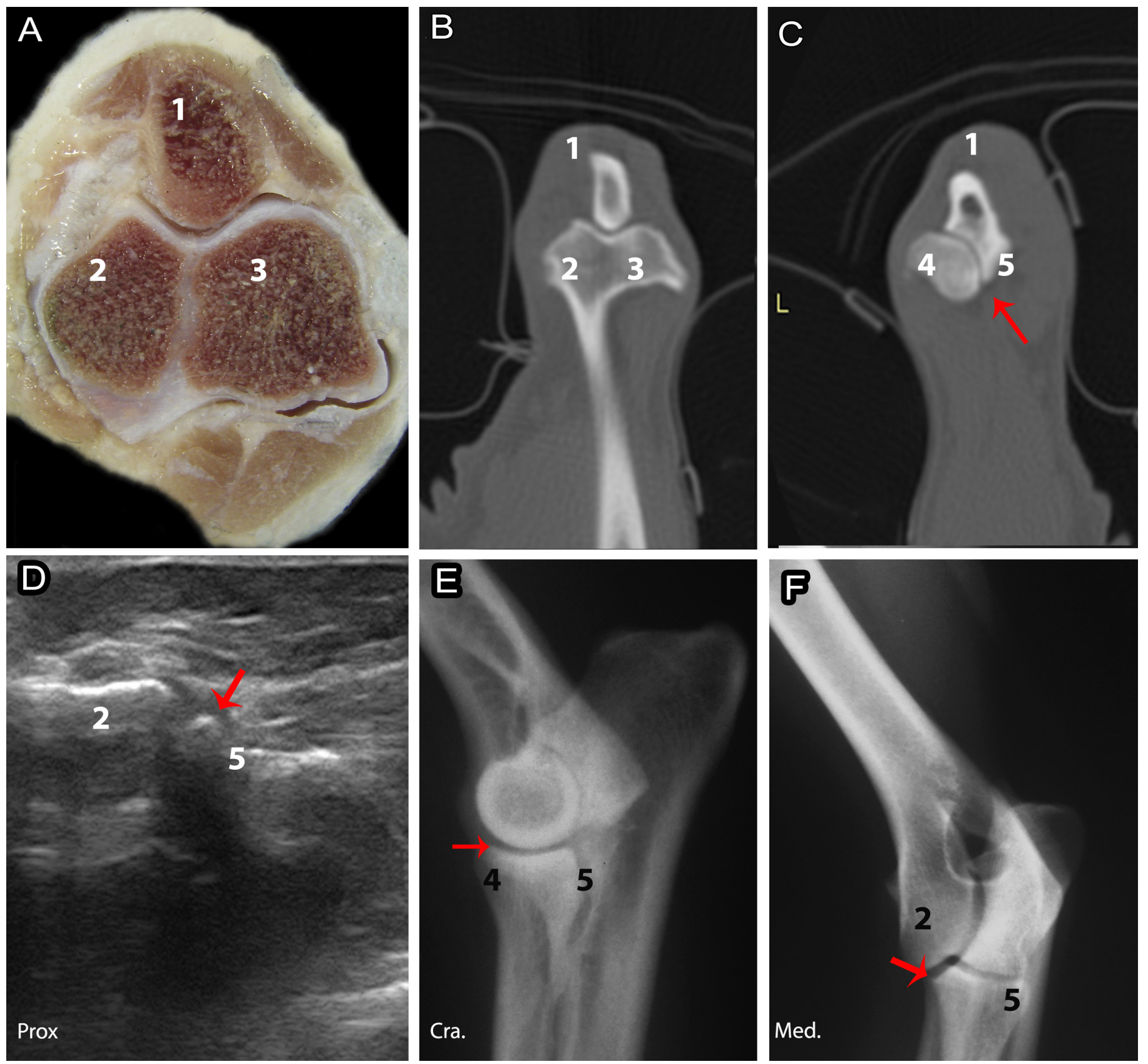

Fig.7. (A) Cross-section anatomy of the region of the humeral condyles. (B) Computed tomography image of the region of the humeral condyles in the transverse plane. (C) Computed tomography image in the transverse plane of the region of the medial coronoid process of the ulna (red arrow). (D) Ultrasonography image in the longitudinal oblique section (craniomedial) in the middle region of the joint with visualization of the medial coronoid process of the ulna (red arrow). (E,F) Radiographic images of the elbow joint in the mediolateral and craniocaudal oblique projections, showing the region referring to the medial coronary process of the ulna (red arrow). Ulnar neck (1), medial humeral condyle (2), lateral humeral condyle (3), radio (4), ulna (5).

Magnetic resonance imaging could be used to examine soft tissues such as muscles, tendons, and ligaments, but the size of the elbow region made it difficult to observe the details. Even as CT could evaluate in transverse sections, being advantage over others techniques. The bone marrow, articular space, and subchondral bone could be clearly visualized, which cannot be fully characterizes in ultrasound technique (Fig.8B-E).
Ligaments (lateral collateral and medial collateral), tendons (triceps brachii muscle tendon) and muscles (triceps brachii, brachii/biceps brachii, flexores and extensors) were the structures that have most clearly visibility in ultrasound in this study. Bones and articular space have limited access, ultrasound only allowed the surface vision with a superficial evaluation. 

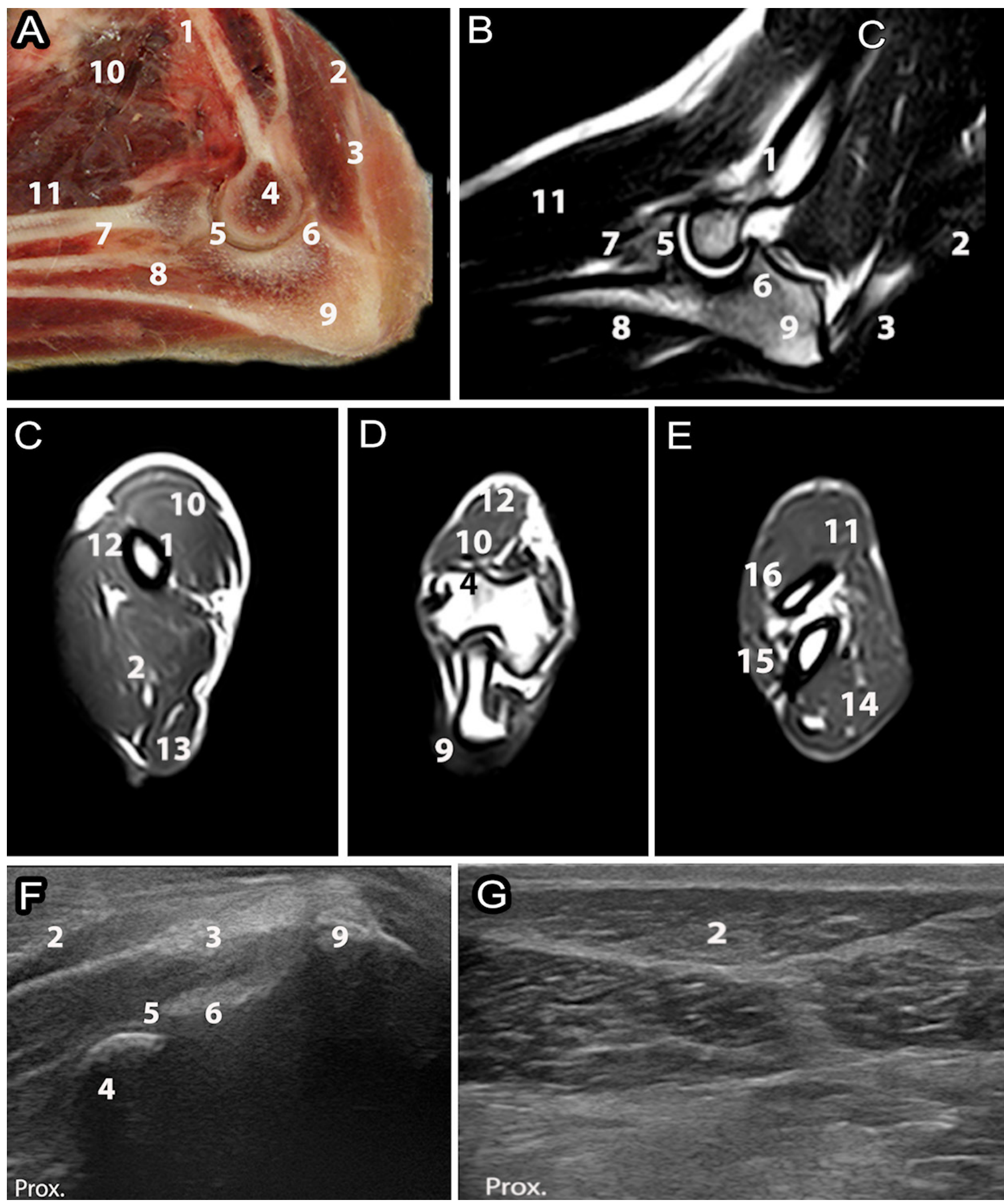

Fig.8. (A) Longitudinal anatomy of the elbow joint region. (B) Magnetic resonance imaging of the longitudinal plane elbow joint on T2-weighted fast spin echo (FSE) sequence. (C) Magnetic resonance imaging in the transverse plane of the proximal region, (D) region of the humeral condyles and (E) distal region in relation to the elbow joint in 3D sequence Hyce. (F) Ultrasonographic image of the caudal face of the elbow region and (G) lateral face in longitudinal plane. Humerus (1), triceps brachial muscle (2), triceps brachial muscle tendon (3), humeral condyle (4), joint space (5), anconeus process (6), radius (7), ulna (8), olecranon (9), biceps brachii muscle (10), carpal radial extensor muscle (11), brachial muscle (12), tensor muscle of the forearm fascia (13), flexor muscles (14), lateral ulnar muscle (15), common digital extensor muscle (16). 


\section{DISCUSSION}

Most of the dogs evaluated in this study were co-operative during the examination, showing the possibility of routine use of ultrasonography. The animals used in this study were healthy, although sedation or anesthesia may be required depending on the level of pain. No previous studies have evaluated this issue.

The ultrasonographic evaluation protocol was created based on previous literature (Lamb \& Wong 2005). The anatomical references used were the same, but this study suggests a refinement of regions division, a detailed description of the structures and transductor position, intended to do a didactic approach as a "step by step".

Results showed identification of most of the structures that was intended to demonstrate by the suggested protocol. Musculoskeletal ultrasonography examination is essential for the identification of structures. Standardization of the ultrasonographic procedure is one of the prerequisites for proper evaluation (Kramer et al. 2001). In this study, prior knowledge of anatomical structures was essential for the identification and description of the structures.

Ligaments showed significant characterization, highlighting collateral ligaments, which can be described as multiple linear hyper-echogenic structures, in agreement with the findings of Villamonte-Chevalier et al. (2015a).

Tendons and muscular structures were identified along with their points of origin and insertion. Ultrasonography allows evaluation of muscle fibers, their morphology, echogenicity, and echotexture. Muscles were described as hypo-echogenic structures with multiple fine hyper-echogenic lines, and the tendons as hyper-echogenic parallel lines, contiguous to the muscle inserted in the bone surface (Knox et al. 2003, Villamonte-Chevalier et al. 2015b).

The articular space was observed as a hypo-echogenic space between the surfaces of the humerus, radius, and ulna (Knox et al. 2003, Lamb \& Wong 2005, Villamonte-Chevalier et al. 2015b). The identification of the articular space is useful when considering interventional procedures guided by ultrasonography.

The subtendinous bursa of the triceps brachii muscle was identified earlier in the study by Villamonte-Chevalier et al. (2015a). The subtendinous bursa was not observed in every animal in this study.

Bone structures were characterized by a hyper-echogenic interface, forming acoustic shadows, which have already been described in literature. It's believed that the technique can identify some discreet changes as bone fragments (Kramer et al. 1997), and could be used as additional technique to radiographic exam.

The medial coronoid process was identified in the oblique plane as a hyper-echogenic region, with acoustic shadows, adjacent to the articular space (Knox et al. 2003). Some morphological changes could be observed on ultrasonography as previously described by Seyrek-Intas et al. (2009). However, computed tomography can provide additional information regarding this region (De Rycke et al. 2002).

Ultrasound is effective to identify the joint space and evaluation of soft tissues specially ligament, tendons and muscles. For bone structures, CT is the chosen technique when radiographs are not sufficient for the diagnosis, CT can show similar information as arthroscopy and identify premature lesions in cases of fragmentation of coronois process. Besides that, is the gold standard technique for elbow incongruence evaluation (Sendyk-Grunkraut et al. 2017). Magnetic ressonance presents a great soft tissues diferenciation, identifying tendons, cartilage and other soft tissues injury (Gielen et al. 2012).

Ultrasound should be used for soft tissues evaluation in places that are not easily accessible using computed tomography and magnetic resonance imaging. One of the factors that lead to limited use of ultrasonography for musculoskeletal evaluation is the small number of professionals who perform this type of evaluation. Musculoskeletal ultrasonography is a difficult, operator-dependent modality with a long learning curve (Nazarian 2008); therefore, it depends on the training of the professionals in the area to disseminate the use of this technique.

\section{CONCLUSIONS}

Ultrasonography is useful for complementary assessment of the ligaments and tendons, and may also provide data about muscular structures. However, further studies are needed to evaluate its capacity for identifying musculoskeletal injuries.

The idea of suggesting a protocol with a description of the structures and anatomical references is interesting to stimulate veterinary students and professionals to deepen their knowledge in this area. A standard protocol is also useful in research.

Acknowledgment. The authors thank Prof. Luiz Carlos Vulcano by computerized tomography examination, Universidade Estadual Paulista-Botucatu, Felipe Suarez for the magnetic resonance examination, (Diagnostic Imaging Center: PROVET), Prof. Carlos Eduardo Ambrósio and Fábio Cury for the anatomical sections (FZEA-USP)

Conflict of interest statement.- The authors have no competing interests.

\section{REFERENCES}

Brienza P.D. \& Lacreta Júnior A.C.C. 2013. Ressonância magnética na avaliação da articulação do joelho em cães. Proceedings Congresso de Pós-Graduação da Universidade Federal de Lavras, Lavras, MG.

Cook C.R. \& Cook J.L. 2009a. Diagnostic imaging of canine elbow dysplasia: a review. Vet. Surg. 38(2):144-153. <http://dx.doi.org/10.1111/j.1532950X.2008.00481.x><PMid:19236671>

Cook J.L. \& Cook C.R. 2009b. Bilateral shoulder and elbow arthroscopy in dogs with forelimb lameness: diagnostic findings and treatment outcomes. Vet. Surg. 38(2):224-232. <http://dx.doi.org/10.1111/j.1532-950X.2008.00490. x><PMid:19236681>

De Rycke L.M., Gielen I.M., van Bree H. \& Simoens P.J. 2002. Computed tomography of the elbow joint in clinically normal dogs. Am. J. Vet. Res. 63(10):1400-1407. <http://dx.doi.org/10.2460/ajvr.2002.63.1400> <PMid:12371767>

Gielen I., Kromhout K., Dingemanse W. \& Van Bree H. 2012. Update on diagnostic imaging in elbow disease. Proceedings 27th Annual Meeting of the International Elbow Working Group, Birmingham, p.13-14.

Knox 4th V.W., Sehgal C.M. \& Wood A.K.W. 2003. Correlation of ultrasonographic observations with anatomic features and radiography of the elbow joint in dogs. Am. J. Vet. Res. 64(6):721-726. <http://dx.doi.org/10.2460/ ajvr.2003.64.721 ><PMid:12828258>

Kramer M., Gerwing M., Hach V. \& Schimke E. 1997. Sonography of the musculoskeletal system in dogs and cats. Vet. Radiol. Ultrasound 
38(2):139-149. <http://dx.doi.org/10.1111/j.1740-8261.1997.tb00829. $\mathrm{x}><$ PMid:9238783>

Kramer M., Gerwing M., Sheppard C. \& Schimke E. 2001. Ultrasonography for the diagnosis of diseases of the tendon and tendon sheath of the biceps Brachii muscle. Vet. Surg. 30(1):64-71. <http://dx.doi.org/10.1053/ jvet.2001.20336><PMid:11172462>

Lamb C.R. \& Wong K. 2005. Ultrasonographic anatomy of the canine elbow. Vet. Radiol. Ultrasound 46(4):319-325. <http://dx.doi. org/10.1111/j.1740-8261.2005.00060.x><PMid:16229434>

Nazarian L.N. 2008. The top 10 reasons musculoskeletal sonography is an important complementary or alternative technique to MRI. Am. J. Roentgenol. 190(6):1621-1626. <http://dx.doi.org/10.2214/AJR.07.3385> <PMid:18492916>

Samii V.F. \& Long C.D. 2002. Musculoskeletal system, p.267-291. In: Mattoon J.S. \&. Nyland T.G. (Eds), Small Animal Diagnostic Ultrasound. 2nd ed. Saunders, Philadelphia.

Sendyk-Grunkraut A., Martín C.M., Souza A.N.A., Patrício G.C.F., Loriga dos C.A.B., Matera J.M. \& Fonseca-Pinto A.C.B.C. 2017. Avaliação morfológica e morfométrica da articulação umerorradioulnar em cães. Pesq. Vet. Bras. 37(2):160-170. <http://dx.doi.org/10.1590/ s0100-736x2017000200011>

Seyrek-Intas D., Michele U., Tacke S., Kramer M. \& Gerwing M. 2009. Accuracy of ultrasonography in detecting fragmentation of the medial coronoid process in dogs. J. Am. Vet. Med. Assoc. 234(4):480-485. <http://dx.doi. org/10.2460/javma.234.4.480 > <PMid:19222356>

Van der Meulen G. 2013. Biomechanical considerations in total elbow replacement. Proceedings American College of Veterinary Surgeons Veterinary Symposium, San Antonio, TX, p.437-440.

Villamonte-Chevalier A., Soler M., Sarria R., Agut A., Gielen I. \& Latorre R. 2015a. Ultrasonographic and anatomic study of the canine elbow joint. Vet. Surg. 44(4):485-493. <http://dx.doi.org/10.1111/j.1532-950X.2014.12249. $\mathrm{x}><$ PMid:25069857>

Villamonte-Chevalier A.A., Van Bree H., Broeckx B.J.G., Dingemanse W., Soler M., Van Ryssen B. \& Gielen I. 2015b. Assessment of medial coronoid disease in 180 canine lame elbow joints: a sensitivity and specificity comparison of radiographic, computed tomographic and arthroscopic findings. BMC Vet. Res. 11(1):243. <http://dx.doi.org/10.1186/s12917-015-0556-9> <PMid:26407863> 